\title{
RT-qPCR assay on the vitamin D receptor gene in type 2 diabetes and hypertension patients in Turkey
}

\author{
H.C. Vural ${ }^{1}$ and E. Maltas ${ }^{2}$ \\ ${ }^{1}$ Molecular Biology, Department of Biology, Faculty of Science, \\ Selcuk University, Konya, Turkey \\ ${ }^{2}$ Biochemistry, Department of Chemistry, Faculty of Science, \\ Selcuk University, Konya, Turkey \\ Corresponding author: E. Maltas \\ E-mail: esramaltas@gmail.com
}

Genet. Mol. Res. 11 (1): 582-590 (2012)

Received February 17, 2011

Accepted February 6, 2012

Published March 14, 2012

DOI http://dx.doi.org/10.4238/2012.March.14.1

\begin{abstract}
RT-qPCR was used to analyze the vitamin D receptor (VDR) gene TaqI polymorphism in 100 Turkish patients with type 2 diabetes mellitus (T2DM) and hypertension compared with 100 healthy subjects, to determine whether VDR could be considered as one of the susceptibility genes for T2DM and hypertension. Genotyping was done with PCR, followed by melting curve analysis with specific fluorescent hybridization probes. The results showed that distributions for TT, Tt and $t$ genotypes were 51,46 and $3 \%$ in the patient group, and 35, 49 and $16 \%$ in the control group, respectively. The frequency of the T allele in patients was also significantly higher than that in controls. Based on the results, the relationship between the VDR gene TaqI polymorphism and T2DM patients in the Turkish population was compared. In terms of the genotype distributions and allele frequencies of the VDR gene TaqI polymorphism, there was no statistically significant difference $(\mathrm{P}>0.05)$ between the T2DM and hypertension patients and controls. Application of RT-qPCR method enabled us to assess the prevalence
\end{abstract}


of the VDR gene TaqI polymorphism and its association with type 2 diabetes and hypertension.

Key words: Diabetes mellitus; Hypertension; VDR gene; RT-qPCR; Polymorphism

\section{INTRODUCTION}

Type 2 diabetes mellitus (T2DM), formerly called non-insulin-dependent diabetes mellitus, obesity-related diabetes, or adult-onset diabetes, is a metabolic disorder that is primarily characterized by insulin resistance, relative insulin deficiency and hyperglycemia. Several genes such as glucokinase, hepatocyte nuclear factors, insulin promoter factors, and possibly the insulin and insulin receptor genes are markers for diabetic gene defects. Vitamin D deficiency is also indicative for diabetes. Vitamin D receptor (VDR) is a 1,25-dihydroxyvitamin D3 $\left[1,25(\mathrm{OH})_{2} \mathrm{D} 3\right]$-activated member of the nuclear receptor superfamily of transcription factors. Furthermore, vitamin D3 receptors are intracellular proteins that mediate the nuclear action of the active metabolite 1,25(OH) 2 D3 (Han et al., 1998; Taverna, 2002; Uitterlinden et al., 2004a; Ferré, 2004; Valdivielso and Fernandez, 2006). They play critical roles in calcium homeostasis, bone development and mineralization, as well as control of cell growth and differentiation. Vitamin D deficiency, common in the Turkish population, is a risk factor for metabolic syndrome, T2DM, and ischemic heart disease. Based on amplification of the VDR gene TaqI site by conventional PCR, comparison of the VDR genotypes between the controls and patients with T2DM and hypertension revealed significant differences at the TaqI site, but no differences were found at the ApaI and FokI sites. TaqI polymorphism could be a useful marker linked with the regulation of a candidate risk factor for Turkish patients with type 2 diabetes and hypertension (Dilmec et al., 2010). As these loci have convenient restriction sites, detection of genetic variants has conventionally required single-strand conformation polymorphism (SSCP) and direct sequence analysis, which are both labor-intensive and time-consuming, especially in large-scale analysis. The genomics revolution for complex diseases has not yet sufficiently matured to become a part of clinical practice. Although major research efforts are underway to identify new genetic targets associated with the common complex cardiovascular and metabolic diseases (hypertension, coronary artery disease, adiposity, T2DM), there is currently no such testing successfully established in clinical practice or for the prediction and prevention of the complex diseases. Real-time qPCR expands the influence of PCR-based innovations and presents intriguing directions for the future of biomedical sciences especially molecular diagnostics and molecular physiology and life science (Vrettou et al, 2003). Real-time PCR simply refers monitoring while the amplification is occurring by using fluorescent reagent. The real-time PCR allows the researcher to amplify target gene with low amount of starting DNA (Mullis, 1990; Mir and Southern, 2000). During amplification, how quickly the fluorescent signal reaches a threshold level correlates with the amount of original target sequence, thereby enabling quantification. In addition, the final product can be further characterized by subjecting it to increasing temperatures to determine when the double-stranded product "melts". This melting point is a unique property dependent on product length and nucleotide composition. To accomplish these tasks, conventional PCR has been coupled to state of the art fluorescent chemistries and instrumentation to become real-time PCR (Mullis and Faloona, 1987; Kwok, 
2000). Despite the development of commercial master-mixes containing standardized concentrations of some PCR reagents, the standardization of the primers still poses a significant problem. However, high-quality performance characteristics associated with this technique include throughput, reproducibility, specificity, and sensitivity. RT-qPCR can arise from the use of laboratory equipment and reagent preparation associated with the initial DNA extraction procedure. Additionally, recent studies have examined the underlying mathematical model associated with RT-qPCR, inclusive of the precision of replicate standard curves (Vrettou et al., 2003). As realtime quantitative PCR (RT-qPCR) is increasingly being relied upon for the enforcement of legislation and regulations dependent upon the trace detection of DNA, focus has increased on the quality issues related to the technique.

In this study, genotyping was accomplished using PCR followed by melting curve analysis with specific fluorescent hybridization probes. The use of melting temperature $(\mathrm{Tm})$ proved to be accurate and convenient for detecting point mutation in large-scale genetic analysis (Ohnmacht et al., 2001; Bustin and Nolan, 2004). The aim of the present study was to determine if the polymorphism of the VDR gene, TaqI, is involved in the development of type 2 diabetes and hypertension in the Turkish population.

\section{MATERIAL AND METHODS}

\section{Patients}

Whole-blood samples from 100 Turkish patients with T2DM (60 males and 40 females) were obtained from the Department of Hematology, Selcuk University Hospital, Konya, by using ethylene-diamine-tetraacetic acid (EDTA) as an anticoagulant. For comparision, 100 healthy nondiabetic subjects ( 70 males and 30 females) were also recruited. The diagnosis of T2DM was based on clinical characteristics, levels of residual insulin, or C-peptide-secretory responses. The healthy nondiabetic individuals were recruited by selecting those who did not have a family history of diabetes and demonstrated normal blood glucose, C-peptide, and insulin levels during a 3-h period after intake of $500 \mathrm{kcal}$ food (meal test). Diabetic and control subjects recruited in this study were matched with respect to age and gender. Informed consent was obtained from each study subject after the nature of the study was fully explained.

\section{DNA extraction from blood samples}

Genomic DNA extraction from blood of patients with T2DM and hypertension was carried out by using two different procedures including manual and automatic isolation. QIAamp spin columns (QIAGEN GmbH, Hilden, Germany) were used for the extraction and purification of genomic DNA from peripheral blood leukocytes. The EZ1 automatic DNA isolation system (QIAGEN GmbH) was also used for the extraction of genomic DNA from the blood samples. Genomic DNA extraction from the blood of the patients with T2DM and hypertension was performed using an EZNA blood DNA isolation kit.

\section{Amplification and cloning of the VDR gene TaqI by conventional PCR}

The VDR gene TaqI was amplified from human DNA with designed primer pairs 
(http://biotools.umassmed.edu/bioapps/primer3_www.cgi) and analyzed by OLIGO Analyzer. All reverse primers were the inverse complement. Primer sequences were as follows: VDR gene TaqI forward primer: 5'-CAGAGCATGGACAGGGAGCAA-3' and VDR gene TaqI reverse primer: 5'-GCAACTCCTCATGGGCTGAGGTCTCA-3'.

The PCR was carried out in a total volume of $20 \mu \mathrm{L}$, containing $100 \mu \mathrm{M}$ dNTP, 600 $\mathrm{nM}$ forward primer, $600 \mathrm{nM}$ reverse primer, $1 \mathrm{mM} \mathrm{MgCl}$ and $1.25 \mathrm{U}$ Taq Gold polymerase (Applied Biosystems, Life Technologies Corp., Carlsbad, CA, USA). The amplification reaction was subjected to one cycle of denaturation and activation of polymerase at $95^{\circ} \mathrm{C}$ for 10 min and 30 cycles of denaturation at $95^{\circ} \mathrm{C}$ for $45 \mathrm{~s}$, annealing at $61^{\circ} \mathrm{C}$ for $30 \mathrm{~s}$, and elongation at $72^{\circ} \mathrm{C}$ for $5 \mathrm{~min}$, followed by a final elongation at $72^{\circ} \mathrm{C}$ for $20 \mathrm{~min}$. Following amplification, 5-10 $\mu \mathrm{L}$ PCR product was separated by electrophoresis on $1 \%$ agarose gels in $0.5 \mathrm{X}$ TAE buffer (45 mM Tris-acetic acid, $1 \mathrm{mM}$ EDTA, $\mathrm{pH}$ 8), then, stained with ethidium bromide at 100 $\mathrm{V}$ for $1.5 \mathrm{~h}$ and visualized by UV irradiation. The band size was excised from the agarose gel. DNA was extracted with the QIAquick Gel Extraction Kit, following manufacturer instructions. Each band was examined on an agarose gel. The bands were graded according to their brightness and the presence of non-specific banding patterns.

\section{Analysis of the VDR gene TaqI by RT-qPCR}

\section{The first optimization protocol}

The reverse transcription products were diluted at $1: 15$. The $20-\mu \mathrm{L}$ real-time reaction mixture included $1.33 \mu \mathrm{L}$ diluted RT product, 1X TaqMan Universal PCR Master Mix, and 1X TaqMan assay, which contained the forward and reverse primers as well as the TaqMan probe. Each reaction was run in triplicate on a 96-well plate. Reaction mixture containing no reverse transcription product served as a negative control. The reaction mixture was incubated in an ABI7000 Prism Sequence Detection System for $10 \mathrm{~min}$ at $95^{\circ} \mathrm{C}$, followed by 40 cycles of $95^{\circ} \mathrm{C}$ for $15 \mathrm{~s}$ and $60^{\circ} \mathrm{C}$ for $1 \mathrm{~min}$.

cDNA was diluted to $100 \mu \mathrm{L}$ with water and stored at $-20^{\circ} \mathrm{C}$. PCRs were performed in $20-\mu \mathrm{L}$ mixtures, containing $2 \mu \mathrm{L}$ cDNA (diluted 1:4) and $18 \mu \mathrm{L}$ Fast Start SYBR Green I PCR Mix. For the detection of the VDR gene, real-time qPCR was performed in $20 \mu \mathrm{L}$ using the QuantiFast SYBR Green PCR Kit Quantifast SYBR (QIAGEN, Switzerland). Furthermore, $10 \mu \mathrm{L}$ of each dilution was used as template DNA in Lambda-specific TaqMan assay.

\section{The second optimization protocol}

The quantitation of the DNA levels was carried out by using a real-time fluorescence detection method. cDNA was prepared as described above and amplified by PCR (Bio-Rad, Hemmel Hempstead, Herts, United Kingdom). Primers for the TaqI gene of human primers were designed according to the literature (Han et al., 1998; Foy and Parkes, 2001; Bustin and Nolan, 2004; Ausubel et al., 2005) as follows: human TaqI forward: 5'-CAGAGCATGGACAGGGAGCAA3' and human TaqI reverse: 5'-GCAACTCCTCATGGGCTGAGGTCTCA-3'.

Each experiment was performed in a $50-\mu \mathrm{L}$ reaction volume including $25 \mu \mathrm{L}$ SYBR Green PCR master mix (Applied Biosystems) including $1 \mu \mathrm{L}$ of each $10 \mathrm{mM}$ primer, $4 \mu \mathrm{L} 50$ ng DNA, and $19 \mu \mathrm{L}$ distilled, deionized water $\left(\mathrm{ddH}_{2} \mathrm{O}\right)$. In the last tube, $4 \mu \mathrm{LddH}_{2} \mathrm{O}$ was added 
as a non-template control. The thermal cycling program consisted of an initial denaturation by 1 cycle of $5 \mathrm{~min}$ at $95^{\circ} \mathrm{C}$, followed by 40 cycles of $30 \mathrm{~s}$ at $95^{\circ} \mathrm{C}, 40 \mathrm{~s}$ at $58^{\circ} \mathrm{C}$, and $40 \mathrm{~s}$ at $72^{\circ} \mathrm{C}$. After real-time PCR, a melting curve was obtained by increasing the temperature from $60^{\circ}$ to $95^{\circ} \mathrm{C}$ with a temperature transition rate of $0.1^{\circ} \mathrm{C} / \mathrm{s}$ by the Bio-Rad RT-QPCR software. Each experiment was repeated three times.

\section{Statistical analysis}

Statistical analysis was performed using the SPSS (Version 13.0) statistical analysis software. The difference in allele or genotype frequencies in all patient and control groups was determined by the chi-square test. All tests were two-sided, and differences were considered to be not significant when $P$ values were $>0.05$. The differences of observed alleles and genotypes between the groups were tested using this test after grouping homozygous and heterozygous genotypes. Although the results were not statistically significant, they were consistent with results published in the literature, the positive and/or negative variant genotypes were less frequent in type 2 diabetes and hypertension patients. Where the negatives as controls do not contain any target DNA, the positives contain target DNA (DNA of patients) in the positive/negative assay. It can be concluded that no contaminants occurred.

\section{RESULTS AND DISCUSSION}

Diabetes is a term used for an evolving complex of metabolic derangements that contribute to an impressive list of chronic and disabling conditions. Complex disorders are present due to numerous interactions among environmental, genetic, and endogenous factors (Han et al., 1998). There are two types of diabetes mellitus: insulin-deficient type 1 diabetes mellitus and T2DM (Laaksonen, 2002; Ferré, 2004; Uitterlinden et al., 2004b). T2DM, formerly called non-insulin-dependent diabetes mellitus, obesity-related diabetes, or adult-onset diabetes is a metabolic disorder that is primarily characterized by insulin resistance, relative insulin deficiency and hyperglycemia (Valdivielso and Fernandez, 2006). However, the genetics of this form of diabetes are complex and not clearly defined. Several genes involved in its metabolic pathway have been regarded as good candidates, such as the VDR gene located on chromosome 12 for T2DM, cancer and cardiovascular disease (Malecki et al., 2003). The VDR gene is a central regulator in this endocrine system, and therefore, it is an interesting candidate gene for genetic studies. Several genetic variations have been identified in the VDR gene. Inflammatory and immune responses have been suggested to play a role in the pathogenesis of T2DM (Minamitani et al., 1998; Langenberg et al., 2005). Recent evidence on the linkage and genome association with the research on T2DM has implicated a region of chromosome 1q arm, encompassing the C-reactive protein gene locus (1q21-23, GeneID 1401) with the risk of T2DM in various ethnic study populations (Albanes et al., 1988; Elenitoba-Johnson et al., 2001; Brand et al., 2003). It is necessary to detect and quantify nucleic acids in the genetic analysis of clinical samples and medical diagnosis. RT-qPCR is increasingly recognized as a powerful analytical technique for many trace DNA detection strategies across a diverse range of the areas encompassed within bioanalytical science (Vrettou et al., 2003; Bustin and Nolan, 2004). Real-time PCR uses fluorescent reporter molecules to monitor the production of the amplification products 
during each cycle of the PCR. This combines the DNA amplification and detection stages into a homogeneous assay and obviates the need for gel electrophoresis to detect amplification products. Real-time qPCR has made it possible to accurately, reliably and reproducibly quantify starting amounts of the nucleic acids during the PCR without the need for postPCR analysis. At the end of the amplification, the reaction mixture was discarded without opening the tube, thus avoiding contamination of the laboratory with PCR product (Jousilahti et al., 2000). However, RT-PCR is an high sensitivity, inexpensive and time-saving method compared with conventional PCR methods. It also offers reliable, reproducible and high-sensivity gene amplification for clinical application (La Batide-Alanore et al., 2003). So far only two polymorphisms have been reported in the coding exons of the VDR gene.

In this study, cDNA obtained from patient and control groups was used for SYBR green quantitative PCR and TaqI primer pairs of the VDR gene, for control $\lambda$ DNA (Bacteriophage-Roche, Roche Diagnostics Corp., Indianapolis, IN, USA) to form a standard curve for determination of the VDR gene activation in patients with T2DM and hypertension. The threshold value was manually set above the baseline displayed in the amplification plot after completion of the RT-qPCR. Relative quantification of gene amplification was evaluated by utilizing the comparative critical threshold $(\mathrm{Ct})$. The $\mathrm{Ct}$ values for each mature DNA reaction were subtracted from the respective $\mathrm{Ct}$ values of the control $\lambda$ DNA (Bacteriophage-Roche), resulting in the $\Delta \mathrm{Ct}$ value. The largest $\Delta \mathrm{Ct}$ value was arbitrarily used as a constant that was subtracted from all other $\Delta \mathrm{Ct}$ values to determine a $\Delta \Delta \mathrm{Ct}$ value. Fold changes were then generated for each mature DNA by calculating $2^{-\Delta \Delta \mathrm{Ct}}$.

The emission of fluorescence was a function of the cycle number and was determined by using the sequence detector software. The value of the cycle number is linearly correlated with the logarithmic value of the amount of TaqI genomic DNA. Fluorescence was detected continuously throughout this process and was plotted graphically as fluorescence $v s$ temperature. Melting curve analysis was achieved by decreasing the temperature. The differences in Tm of real-time PCR products showed nonspecific products and primer dimers in all products. A series of RT-qPCR protocols illustrated the essential technical stages required to generate quantitative data, which were reliable and reproducible (Figures 1, 2, 3, and 4). According to the melting curve, all data were evaluated. In comparison to the VDR genotypes between the controls and T2DM patients related to the analysis, results revealed a significant difference at the TaqI site by the RT-qPCR described in this study. Distribution for TT, Tt and tt genotypes were 51,46 and $3 \%$ in the patient group and 35, 49 and $16 \%$ in the control group, respectively. Frequencies for $\mathrm{T}$ and $\mathrm{t}$ alleles were 74 and $26 \%$ in the patient group and 59.5 and $40.5 \%$ in the control group, respectively (Table 1). The frequency of the $\mathrm{T}$ allele in patients was also significantly higher than that in controls. We also demonstrated that the TT genotype may not be related to VDR gene polymorphisms, but also associated in the patients with T2DM in the Turkish population. Consequently, this TaqI polymorphism could be a useful marker linked with the regulation of a candidate risk factor in Turkish patients with T2DM and hypertension. We also attempted to quantify the magnitude of the relationship between any identified variants of the VDR gene and T2DM and various intermediate outcomes including plasma glucose, insulin sensitivity and vitamin D. The genotype distributions of the VDR gene TaqI polymorphism were in agreement with the statistical analysis expectations in the patient and control groups $(\mathrm{P}>0.05)$. Moreover, there was no correlation between VDR gene TaqI polymorphism genotypes and the clinical characteristics of patients and controls. 


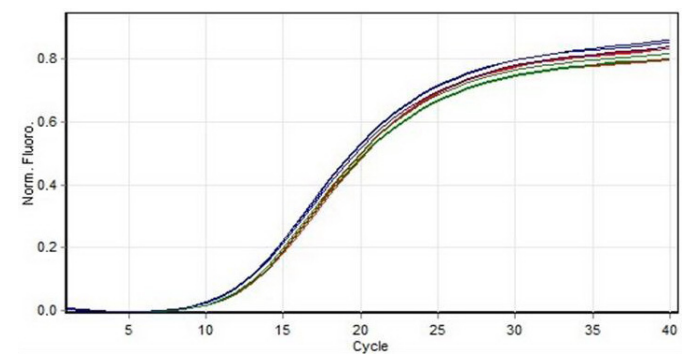

Figure 1. Amplification and standard curves.

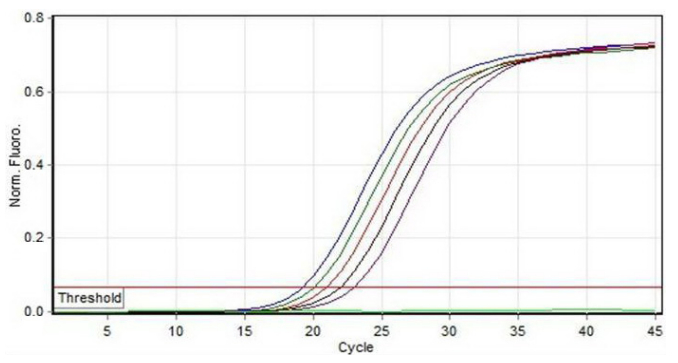

Figure 2. Quantitation data for cycling cDNAs in T2DM patients.

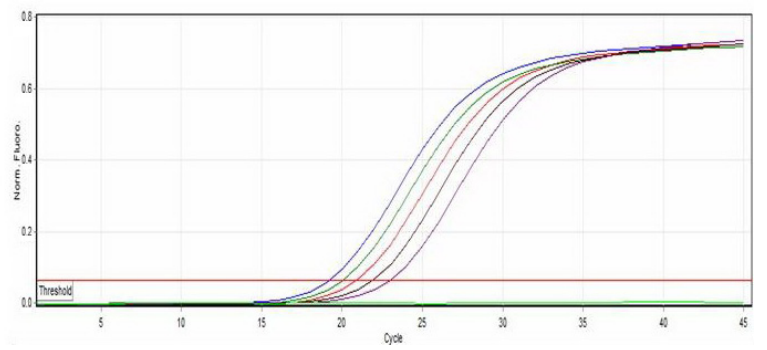

Figure 3. Determination of efficiency and gene copy numbers using five-color multiplexing samples. The efficiency of amplification was established for five targets within a run using color multiplexing and used the calculated efficiencies to determine gene amplification in T2DM patients.

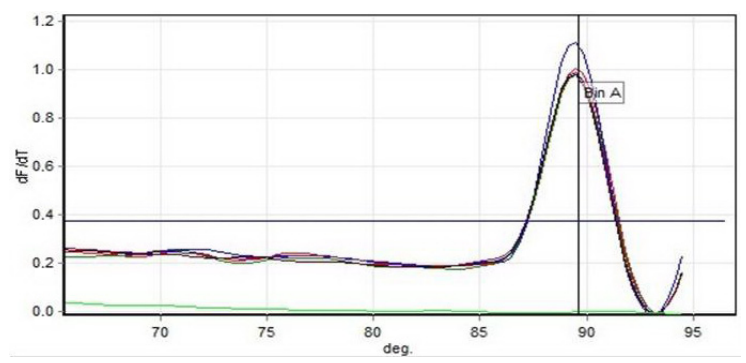

Figure 4. Melting curve analysis results in a single peak for each positive sample, proving the amplification of only the specific target sequence. 
Table 1. Distribution of vitamin D receptor gene TaqI polymorphism genotypes and allele frequencies between T2DM and hypertension patients and control groups.

\begin{tabular}{|c|c|c|c|c|c|c|c|}
\hline & \multicolumn{3}{|c|}{ Distribution of genotypes $(\mathrm{N})$} & \multicolumn{4}{|c|}{ Allele frequencies $[\mathrm{N}(\%)]$} \\
\hline & $\mathrm{TT}$ & $\mathrm{Tt}$ & $\mathrm{tt}$ & \multicolumn{2}{|c|}{ T allele } & \multicolumn{2}{|c|}{$\mathrm{t}$ allele } \\
\hline Patients & 51 & 46 & 3 & 148 & $(74 \%)$ & 52 & $(26 \%)$ \\
\hline Controls & 35 & 49 & 16 & 119 & $(59.5 \%)$ & 81 & $(40.5 \%)$ \\
\hline
\end{tabular}

This method are believed to be accessible to researchers in order to provide reliable data based on the described protocol in this study. RT-qPCR is essential for accurate gene quantification. As regards the advantages of the method, there is a large dynamic range of quantification, no requirement for post-PCR sample handling and the need for only very small amounts of starting material. In conclusion, allelic differences in the VDR gene may contribute to the genetic predisposition to certain diseases. As vitamin D modulates insulin secretion, it is feasible that genetic variants of the VDR gene may contribute to the development of T2DM. Finally, our data affirm the association of VDR polymorphism in combination of genotypes with risk of T2DM in the Turkish population.

In accordance with the results on allele frequencies and genotype distributions of the VDR gene TaqI and ApaI polymorphisms in patients with T2DM and hypertension, several authors have also previously reported that allele frequencies and genotype distributions of the VDR gene TaqI polymorphism were not significantly different in patients with diabetes mellitus such as other diseases. In this study, it was suggested that the genotype distribution of VDR gene TaqI polymorphisms in the studied Turkish population was similar to most other populations with T2DM. The present study also did not show such a predisposition in this Turkish study population with T2DM. There was no statistically significant difference between groups with respect to genotype distribution and allele frequencies of the VDR gene TaqI polymorphism $(\mathrm{P}>0.05)$. Further studies with larger and even more varied populations may be performed using other genetic polymorphisms that might be considered to be risk factors for diabetes mellitus and hypertension, to provide important validation for these results.

\section{ACKNOWLEDGMENTS}

Blood samples of patients and healthy individuals for this study were kindly provided by University of Selçuk, Medical Faculty, Meram, Konya, Turkey. We would like to thank the Scientific Research Foundation of Selcuk University (BAP) for supporting this study. We also thank BioRad company for excellent technical assistance.

\section{REFERENCES}

Albanes D, Jones DY, Schatzkin A, Micozzi MS, et al. (1988). Adult stature and risk of cancer. Cancer Res. 48: 16581662.

Ausubel FM, Brent R, Kingston RE, Moore DD, et al. (2005). Current Protocols in Molecular Biology. John Wiley \& Sons, Inc., Hoboken.

Brand CL, Sturis J, Gotfredsen CF, Fleckner J, et al. (2003). Dual PPAR $\alpha / \gamma$ activation provides enhanced improvement of insulin sensitivity and glycemic control in ZDF rats. Am. J. Physiol. Endocrinol. Metab. 284: E841-E854.

Bustin SA and Nolan T (2004). Pitfalls of quantitative real-time reverse-transcription polymerase chain reaction. $J$. Biomol. Tech. 15: 155-166. 
Dilmec F, Uzer E, Akkafa F, Kose E, et al. (2010). Detection of VDR gene ApaI and TaqI polymorphisms in patients with type 2 diabetes mellitus using PCR-RFLP method in a Turkish population. J. Diabetes Complications 24: 186-191.

Elenitoba-Johnson KS, Bohling SD, Wittwer CT and King TC (2001). Multiplex PCR by multicolor fluorimetry and fluorescence melting curve analysis. Nat. Med. 7: 249-253.

Ferré P (2004). The biology of peroxisome proliferator-activated receptors: relationship with lipid metabolism and insulin sensitivity. Diabetes 53 (Suppl 1): S43-S50.

Foy CA and Parkes HC (2001). Emerging homogeneous DNA-based technologies in the clinical laboratory. Clin. Chem. 47: 990-1000.

Han TS, Feskens EJM, Lean MEJ and Seidell JC (1998). Associations of body composition with type 2 diabetes mellitus. Diabet. Med. 15: 129-135.

Jousilahti P, Tuomilehto J, Vartiainen E, Eriksson J, et al. (2000). Relation of adult height to cause-specific and total mortality: a prospective follow-up study of 31,199 middle-aged men and women in Finland. Am. J. Epidemiol. 151: $1112-1120$.

Kwok PY (2000). High-throughput genotyping assay approaches. Pharmacogenomics 1: 95-100.

La Batide-Alanore A, Tregouet DA, Sass C, Siest G, et al. (2003). Family study of the relationship between height and cardiovascular risk factors in the STANISLAS cohort. Int. J. Epidemiol. 32: 607-614.

Laaksonen M, Karkkainen M, Outila T, Vanninen T, et al. (2002). Vitamin D receptor gene BsmI-polymorphism in Finnish premenopausal and postmenopausal women: its association with bone mineral density, markers of bone turnover, and intestinal calcium absorption, with adjustment for lifestyle factors. J. Bone Miner. Metab. 20: 383-390.

Langenberg C, Shipley MJ, Batty GD and Marmot MG (2005). Adult socioeconomic position and the association between height and coronary heart disease mortality: findings from 33 years of follow-up in the Whitehall Study. Am. J. Public Health 95: 628-632.

Malecki MT, Frey J, Moczulski D, Klupa T, et al. (2003). Vitamin D receptor gene polymorphisms and association with type 2 diabetes mellitus in a Polish population. Exp. Clin. Endocrinol. Diabetes 111: 505-509.

Minamitani K, Takahashi Y, Minagawa M, Yasuda T, et al. (1998). Difference in height associated with a translation start site polymorphism in the vitamin D receptor gene. Pediatr. Res. 44: 628-632.

Mir KU and Southern EM (2000). Sequence variation in genes and genomic DNA: Methods for large-scale analysis. Ann. Rev. Genom. Hum. Gen. 1: 329-360.

Mullis KB (1990). The unusual origin of the polymerase chain reaction. Sci. Am. 262: 56-5.

Mullis KB and Faloona FA (1987). Specific synthesis of DNA in vitro via a polymerase-catalyzed chain reaction. Methods Enzymol. 155: 335-350.

Ohnmacht GA, Wang E, Mocellin S, Abati A, et al. (2001). Short-term kinetics of tumor antigen expression in response to vaccination. J. Immunol. 167: 1809-1820.

Taverna MJ, Sola A, Guyot-Argenton C, Pacher N, et al. (2002). Taq I polymorphism of the vitamin D receptor and risk of severe diabetic retinopathy. Diabetologia 45: 436-442.

Uitterlinden AG, Fang Y, van Meurs JB, Pols HA, et al. (2004a). Genetics and biology of vitamin D receptor polymorphisms. Gene 338: 143-156.

Uitterlinden AG, Fang Y, van Meurs JB, van Leeuwen H, et al. (2004b). Vitamin D receptor gene polymorphisms in relation to vitamin D related disease states. J. Steroid Biochem. Mol. Biol. 89-90: 187-193.

Valdivielso JM and Fernandez E (2006). Vitamin D receptor polymorphisms and diseases. Clin. Chim. Acta 371: 1-12.

Vrettou C, Traeger-Synodinos J, Tzetis M, Malamis G, et al. (2003). Rapid screening of multiple beta-globin gene mutations by real-time PCR on the LightCycler: application to carrier screening and prenatal diagnosis of thalassemia syndromes. Clin. Chem. 49: 769-776. 